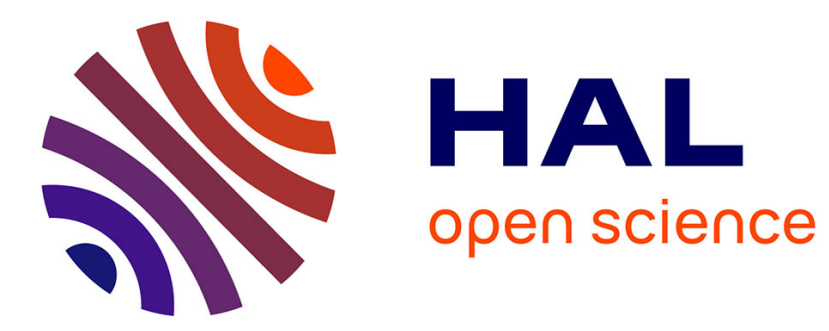

\title{
Electrochromism: from oxide thin films to devices
}

\author{
Aline Rougier, Abdelaadim Danine, Cyril Faure, Sonia Buffière
}

\section{To cite this version:}

Aline Rougier, Abdelaadim Danine, Cyril Faure, Sonia Buffière. Electrochromism: from oxide thin films to devices. SPIE Photonics West 2015: OPTO, Feb 2015, San Francisco, United States. 93641D (10 p.), 10.1117/12.2077577 . hal-03136350

\section{HAL Id: hal-03136350 \\ https://hal.science/hal-03136350}

Submitted on 9 Feb 2021

HAL is a multi-disciplinary open access archive for the deposit and dissemination of scientific research documents, whether they are published or not. The documents may come from teaching and research institutions in France or abroad, or from public or private research centers.
L'archive ouverte pluridisciplinaire HAL, est destinée au dépôt et à la diffusion de documents scientifiques de niveau recherche, publiés ou non, émanant des établissements d'enseignement et de recherche français ou étrangers, des laboratoires publics ou privés. 


\title{
Electrochromism : from oxide thin films to devices
}

\author{
ACQHRougier, AEGHDOAP Danine, C U UAFaure, SRQDBuffière \\ Univ. Bordeaux, ICMCB, UPR 9048, F-33600 Pessac, France \\ aline.rougier@icmcb.cnrs.fr
}

\begin{abstract}
In respect of their adaptability and performance, electrochromic devices, ECDs, which are able to change their optical properties under an applied voltage, have received significant attention. Target applications are multifold both in the visible region (automotive sunroofs, smart windows, ophthalmic lenses, and domestic appliances (oven, fridge...)) and in the infrared region (Satellites Thermal Control, IR furtivity). In our group, focusing on oxide thin films grown preferentially at room temperature, optimization of ECDs performances have been achieved by tuning the microstructure, the stoichiometry and the cationic composition of the various layers. Herein, our approach for optimized ECDs is illustrated through the example of $\mathrm{WO}_{3}$ electrochromic layer in the visible and in the IR domain as well as $\mathrm{ZnO}$ based transparent conducting oxide layer. Targeting the field of printed electronics, simplification of the device architecture for low power ECDs is also reported.

Keywords: Electrochromism, oxide thin films, device
\end{abstract}

\section{INTRODUCTION}

The term electrochromism was first introduced by Platt et al. in 1961, to indicate a colour generated via a molecular Stark effect in which orbitals energies are shifted by an electric field. However, electrochromism as a redox-coloration mechanism, was indeed earlier observed. In 1815, Berzelius showed that pure $\mathrm{WO}_{3}$ (which is pale yellow) changes colour by reduction under a flow of dry hydrogen. In 1824, Wöhler reported a similar effect on the chemical reduction of sodium metal. However, real interest on electrochromism was inspired by the work of Deb et al. at the end of the sixties. Deb described the reversible coloration of $\mathrm{WO}_{3}$ evaporated thin films by UV-irradiation (photochromism) or under an applied voltage [1]. From then, generally speaking, the progress in EC technology has been quite slow with the first known commercialization of electrochromic devices, ECDs, in 1988 with the astonishing success of Gentex Corporation [2] on the self's darkening rear view mirrors using a technology based on liquid electrochromic species, the modified viologens. Since then, it has been a commercial success with about 100 million pieces sold all over the world. Rear-view mirrors are now a market of about 2.5 Million US dollars. From then, a few products including goggles [3], helmet visors [4] have entered the market. Among other limitations, the development of smart windows has, for a long time, suffered from a poor durability. The first generation smart windows ECDs based on a couple of inorganic electrochromic layers, namely $\mathrm{WO}_{3} / \mathrm{IrO}_{2}$, was introduced by Saint Gobain in 1985 and then stopped in 1995 for lack of cycling life. In the early 2000s, smart windows or chromogenic glazing for architectural use were introduced by PILKINGTON/FLABEG $\mathrm{GmbH}$, and further produced and sold by a Germany's ECONTROL-GLAS GmbH Company [5]. After several years of efforts, Saint Gobain finally developed an all-solid state electrochromic device commercialized as a roof window for the Ferrari Super America in 2008. ECDs for building are now available from few companies, including ChromoGenics, Sage-SaintGobain,... [6]. However, the durability of large area devices as well as the expensive cost remain the limiting issues of a broad commercialization of ECDs. In respect of the development of ECDs active in the IR region, both organic and inorganic materials have been investigated targeting applications of IR furtivity or satellite thermal control [7-8].

Independently of the fields, more and more applications required flexibility and low temperature processing. Thus in our group, low temperature deposition even room temperature deposition is a key criterion, allowing the use of a wide range of substrates including plastic foils and papers. Herein, investigating oxides thin films we will illustrate how one can optimize the electrochromic performances by tuning the thin films characteristics including the structure, the morphology, the composition, as well as by building new devices architecture. In particular, we choose to highlight the progress achieved in our group on $\mathrm{WO}_{3}$ and $\mathrm{ZnO}$ based thin films as single layers while a new concept is reported for low energy devices. 


\section{RESULTS AND DISCUSSION}

\subsection{Few words on ECDs}

Prior to discussion on materials properties, it is worth to describe common electrochromic devices as well as their criteria of merit. A schematic view of an electrochromic device ECD is given in Figure 1. The standard electrochromic devices are based on a five layers stack positioned between two glass substrates or flexible polyester foils [9]. The central part of the device is an ion conductor called electrolyte, organic (an adhesive polymer) or inorganic (generally an oxide film) ensuring the ion exchange between the two electrode materials. Upon application of an electric field, one of the electro-active materials is reduced while the other one is oxidized leading to a change of coloration of at least one of them, inducing color change of the full device. The process is reversible. In order to get a complete system, which will be either colored or bleached, the two materials need to exhibit complementary coloration, or one of them has to be neutral (i.e. no change in color upon oxidation/reduction). Two main families are distinguishable, the anodic materials which are colored in the oxidized state and the cathodic ones colored in their reduced state. All devices utilizing electrochromic color modulation fall within two overlapping categories, according to the mode of operation: electrochromic devices (ECDs) working in transmission (Fig. 2a) or by reflection (Fig. 2b). The key parameters of electrochromic devices include the contrast ratio (color change expressed as the ratio of transmittance between the bleached state and the colored state or of the difference in reflectance ), the - coloration efficiency (coloration obtained as compared to the electrical charge involved), the switching time (rate of coloration and bleaching), the write-erase efficiency and long-term stability (evolution of the coloration and bleaching properties with cycling life).

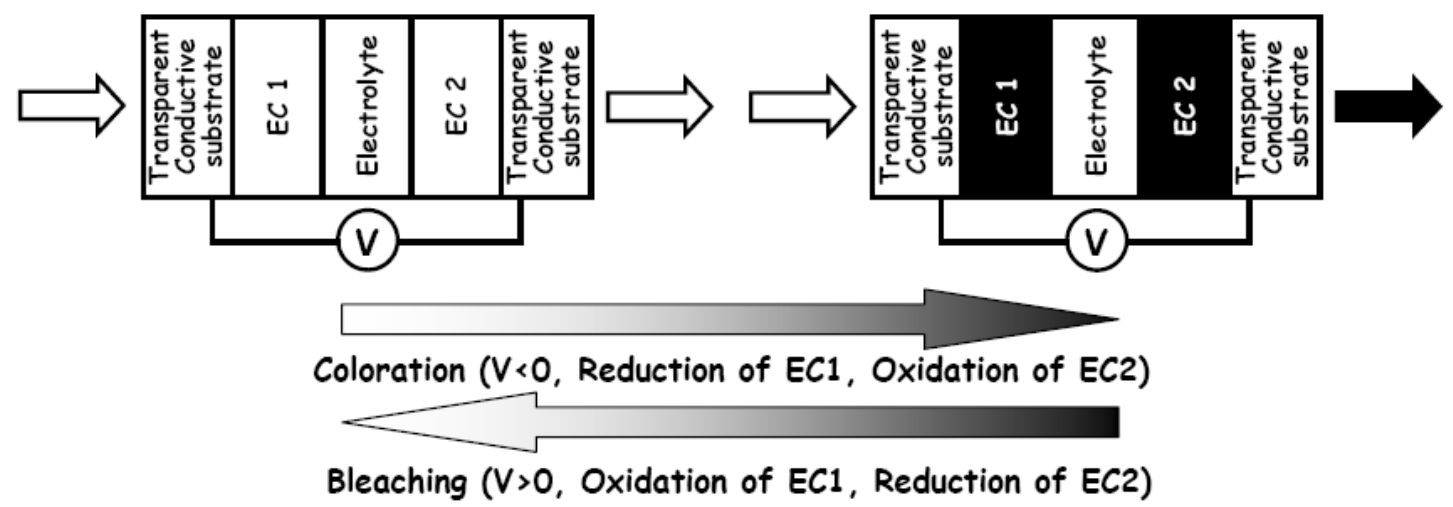

Figure 1: Electrochromic Device based on a five layers configuration described by the TCO/EC1/Elec./EC2/TCO chain in which TCO stands for Transparent Conducting Oxides layer, EC1 and EC2 for Electrochromic layers and Elec. for electrolyte.

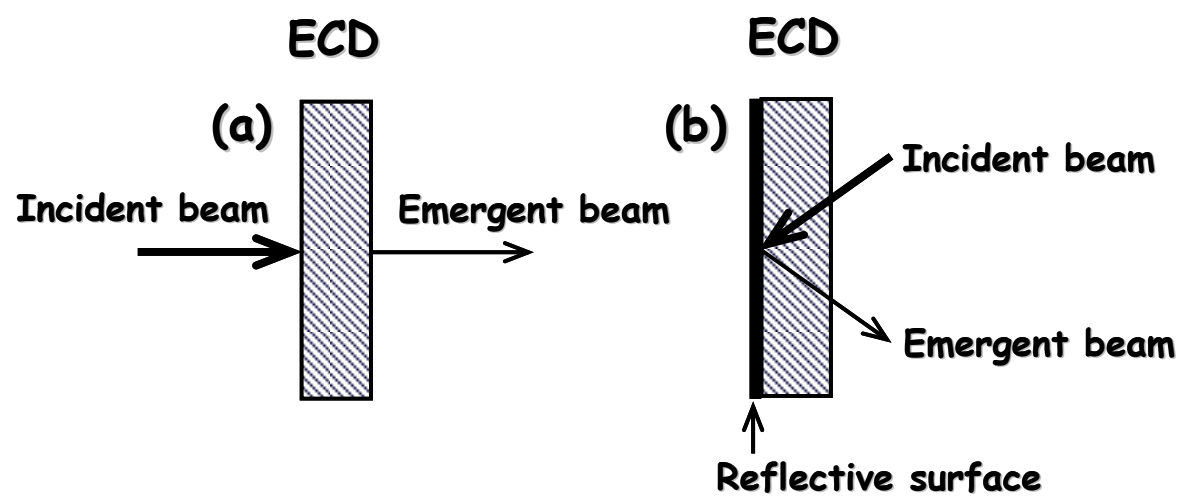

Figure 2: Electrochromic Device (ECD) in a transmittance mode (a) and reflectance mode (b). 


\subsection{Single oxide layers}

\subsection{1. $\mathrm{WO}_{3}$}

Since the discovery of electrochromism, tungsten trioxide, $\mathrm{WO}_{3}$ has emerged as one of the key materials and remains by far the most studied, at least among inorganic systems. Several books and review articles are devoted to this oxide [9-10]. Upon reduction, transparent $\mathrm{WO}_{3}$ thin films switch to a blue colour associated with the formation of $\mathrm{M}_{\mathrm{x}} \mathrm{WO}_{3}$, as a result of the double injection of electron and $\mathrm{M}^{+}$cation, as described by the following equation:

$$
\mathrm{WO}_{3}+\mathrm{xe}^{-}+\mathrm{xM}^{+} \leftrightarrows \mathrm{M}_{\mathrm{x}} \mathrm{WO}_{3}
$$

A reversible switch to the initial transparent state is observed on the following oxidation. However, despite a huge amount of work the mechanism at the origin of the coloration amorphous or crystalline $\mathrm{WO}_{3}$ is still the subject of many controversies. Part of the controversies comes from the numerous deposition conditions used to synthesize $\mathrm{WO}_{3}$ thin films, leading to films exhibiting either non stoichiometry or different morphologies, for instance. Indeed in our group, deposition of $\mathrm{WO}_{3}$ thin films was recently achieved by using a novel synthesis method involving the connection of tungsten oxide nanoparticles by UV-irradiation [11]. Crystallized $\mathrm{WO}_{3}$ thin films, deposited on paper substrate covered with a conductive Ag layer, exhibit various morphologies (Fig. 3) associated with higher electrochemical performances for the films prepared from higher specific surface area homemade $\mathrm{WO}_{3}$ powder $\left(\mathrm{WO}_{3 \text { Syn.) }}\right.$. The ex-situ evolution of the

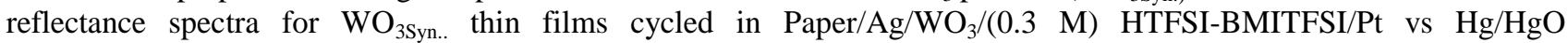
electrochemical cell and progressively colored at various potentials is depicted in Figure 4.
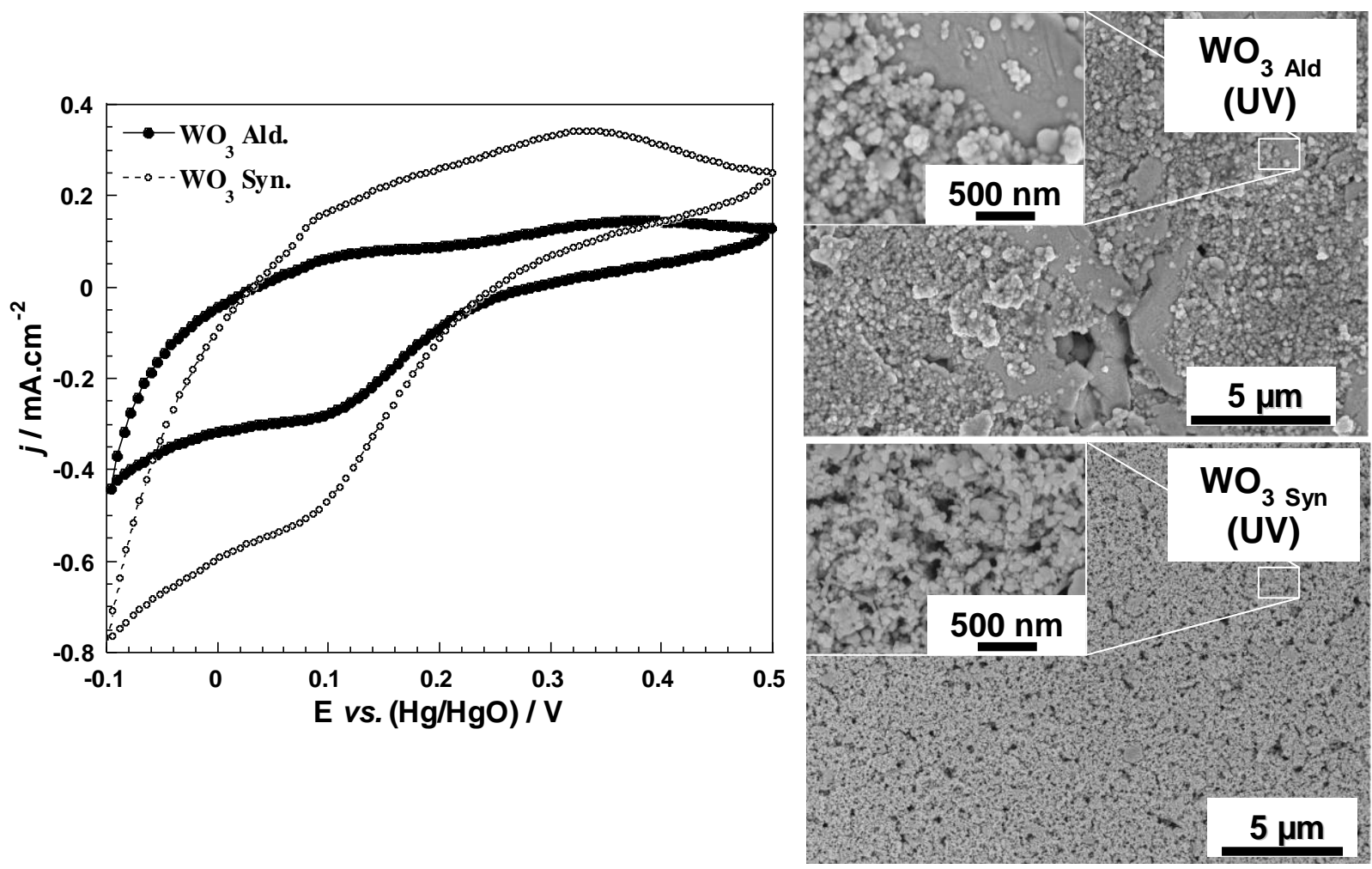

Figure 3: Comparison of $2^{\text {nd }}$ Cyclic Voltammograms of $\mathrm{WO}_{3 \text { Ald. }}$ (From Aldrich powder) and $\mathrm{WO}_{3 \text { syn. }}$ (from home made synthesized powder) thin films cycled in $\mathrm{WO}_{3} / 0.3 \mathrm{M}$ HTFSI in BMITFSI/ $\mathrm{Pt} v s . \mathrm{Hg} / \mathrm{HgO}$ cells with a scan rate of 10 $\mathrm{mV} / \mathrm{s}$ and HRSEM images of $\mathrm{WO}_{3 \text { Ald. }}$ and $\mathrm{WO}_{3 \text { Syn. }}$ thin films, after UV-treatment (UV). All films are deposited on paper/Ag substrates. 


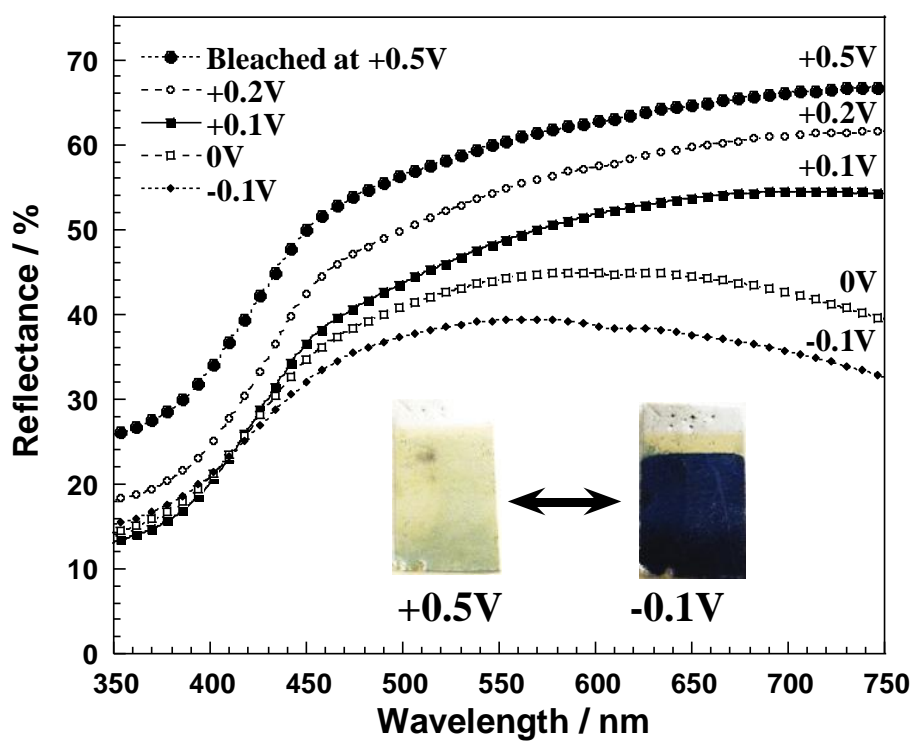

Figure 4: Evolution of the Reflectance Spectra $v s$. wavelength for $\mathrm{WO}_{3 \text { Syn. }}$ colored ex-situ at various applied potentials $(0.5 \mathrm{~V}, 0.2 \mathrm{~V}, 0.1 \mathrm{~V}, 0 \mathrm{~V},-0.1 \mathrm{~V})$ in $\mathrm{WO}_{3} / 0.3 \mathrm{M}$ HTFSI in BMITFSI/Pt vs $\mathrm{Hg} / \mathrm{HgO}$ cells. Micrographs of the bleached state $+0.5 \mathrm{~V}$ and colored state at $-0.1 \mathrm{~V}$ are added.

The colored-bluish state $(-0.1 \mathrm{~V})$ and the bleached-yellowish state $(+0.5 \mathrm{~V})$ are associated with reflectance values of about $\mathrm{R}_{\mathrm{C}} \approx 39 \%$ and $\mathrm{R}_{\mathrm{B}} \approx 60 \%$ at $550 \mathrm{~nm}$, respectively. It should be noted that the film is very dark in the colored state at $-0.1 \mathrm{~V}$, whereas the bleached step may appear by time to time not completely homogeneous. Indeed, in oxidation a limit in potential of $0.5 \mathrm{~V}(\mathrm{vs} \mathrm{Hg} / \mathrm{HgO})$ was chosen for preventing any instability of the silver layer.

The key role played by the morphology on the electrochromic behavior is further illustrated by extending the EC properties of $\mathrm{WO}_{3}$ thin films towards the IR region. Such characterizations in the 2 to $12 \mu \mathrm{m}$ domain were investigated on $\mathrm{WO}_{3}$ thin films deposited by physical means, namely Pulsed Laser Deposition (PLD) and Radio Frequency Sputtering (RFS). Screening a wide range of oxygen deposition pressures and of substrate temperatures $\left(\mathrm{Ts}<400{ }^{\circ} \mathrm{C}\right.$ ), the former method allowed us to conclude on higher optical properties performances, namely higher contrast in reflectance, for films deposited at room temperature showing lower density [12], whereas the latter was favoured in respect of larger size substrates and suitability for applications. The contrast in reflectance $\Delta \mathrm{R}$, defined as the difference between the integrated $R$ value in the deinserted state and the one in the inserted state $\left(\Delta R=R_{\text {deinserted }}-R_{\text {inserted }}\right)$, was deduced from the reflectance recorded after having applied either the insertion $(-1.9 \mathrm{~V})$ or deinsertion $(+1 \mathrm{~V})$ voltage for $180 \mathrm{~s}$ using a $\mathrm{WO}_{3} /(0.1 \mathrm{M}) \mathrm{H}_{3} \mathrm{PO}_{4} / \mathrm{Pt}$ chain.

Depending on their thickness ranging from 100 to $650 \mathrm{~nm}$, RFS- $\mathrm{WO}_{3}$ thin films deposited with a pressure of 45 mTorr show optical modulation that can reach up to $73 \%$ and $50 \%$ in the MW band and LW band, respectively (Table 1). As an example, the evolutions of the reflectance for $320 \mathrm{~nm}$ as-deposited film, inserted $\mathrm{H}_{\mathrm{x}} \mathrm{WO}_{3}$ and deinserted $\mathrm{WO}_{3}$ films are displayed in Fig. 5a. Interestingly, the promising IR optical properties of RFS- $\mathrm{WO}_{3}$ thin films were checked using infrared imagers as shown in Fig. $5 \mathrm{~b}$ representing the corresponding modulation of luminosity $\mathrm{L}\left(\mathrm{L}=\varepsilon \sigma \mathrm{T}^{4}\right.$ in which $\varepsilon$ is the emissivity and $\mathrm{T}$ the apparent temperature, considering the emissivity of the films is different from the one of the black body $\mathrm{BB}(\varepsilon=1)$ ). Upon proton insertion, the black appearance of the as-deposited (inserted) $\mathrm{WO}_{3}$ turns to a reddish-purple one for $\mathrm{H}_{\mathrm{x}} \mathrm{WO}_{3}$, close to the purple appearance of the $\mathrm{BB}$. This luminance modification is associated with an increase in the apparent temperature from $24{ }^{\circ} \mathrm{C}$, for the deinserted state, to $59{ }^{\circ} \mathrm{C}$, for the inserted one. This variation in apparent temperature of $35^{\circ} \mathrm{C}$ was correlated to a variation of emissivity, $\Delta \varepsilon$, of 0.78 between an inserted state of high emissity (0.86) and a deinserted state of very low emissivity (0.08) (Table 1). As expected from the smaller contrast in reflectance $\left(\mathrm{R}_{\mathrm{LW}}=15 \%<\mathrm{R}_{\mathrm{MW}}=73 \%\right)$, a smaller variation of the apparent temperature of $5{ }^{\circ} \mathrm{C}$ in the LW band was recorded. In agreement with higher contrast in reflectance, a maximum variation in apparent temperature in the band III of $21{ }^{\circ} \mathrm{C}$ is obtained for thicker film (i.e. $650 \mathrm{~nm}$ ) deposited on FTO substrate with a corresponding modulation of emissivity of 0.49 (Table 1). As indicated in Table 1, the substrate nature has also a significant influence on the film property as a $650 \mathrm{~nm} \mathrm{WO}$ thick film deposited on Au substrate shows an intermediate behavior, with similar contrast (30-40\%) in MW and LW bands. For all films, the various levels of emissivity lie in the 0.86 to 0.08 range. 


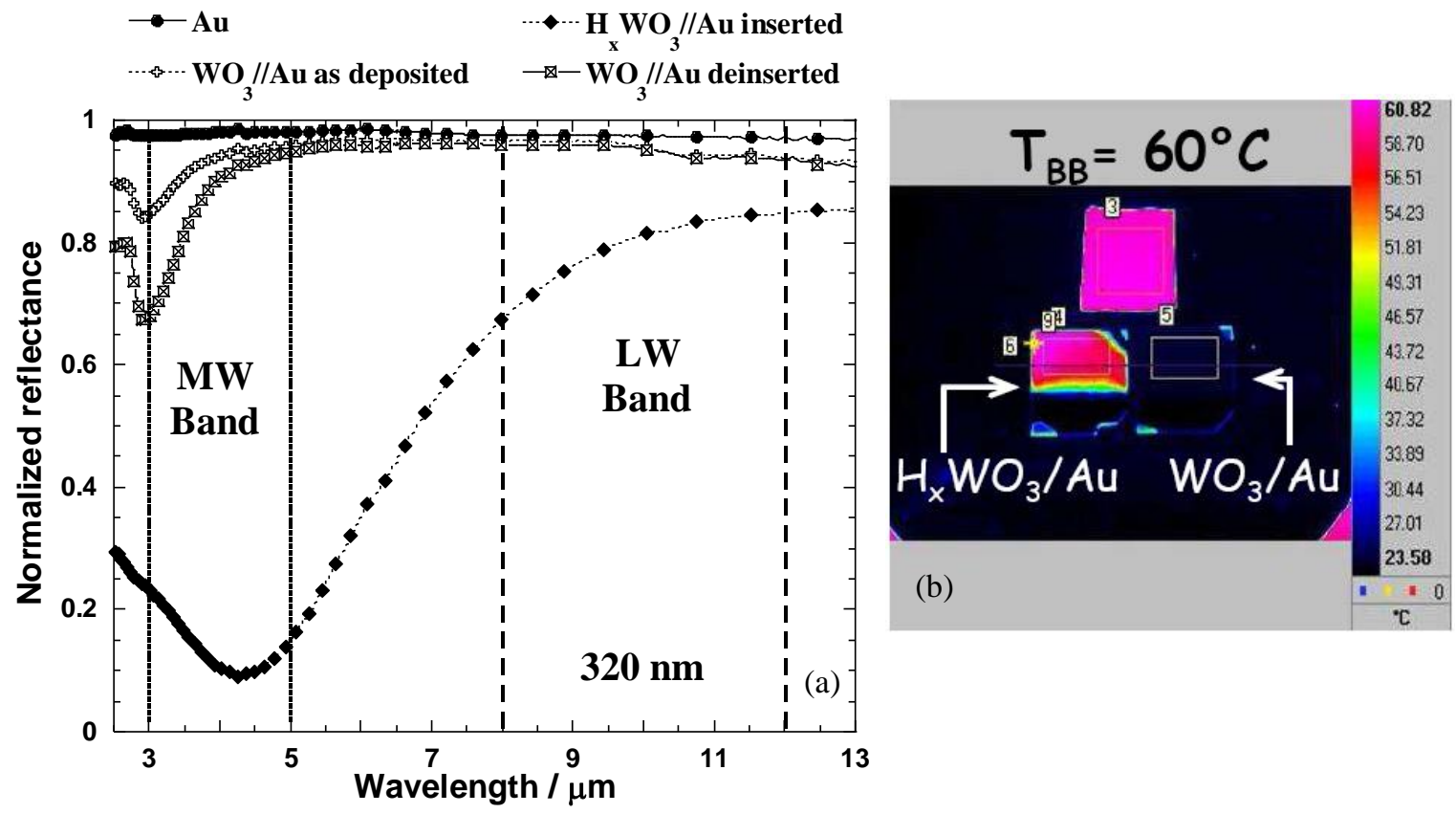

Figure 5: (a) Normalized Reflectance for Au blank substrate, and $320 \mathrm{~nm}$ RFS- $\mathrm{WO}_{3}$ in the as-deposited state, inserted $(-1.9 \mathrm{~V})$, and deinserted one $(1 \mathrm{~V})$. (b) Corresponding thermal camera picture, using an IR imager working in the MW (3-5 $\mu \mathrm{m})$ band, in the inserted state $\left(\mathrm{H}_{\mathrm{x}} \mathrm{WO}_{3}\right)$ and deinserted one $\left(\mathrm{WO}_{3}\right) . \mathrm{T}_{\mathrm{BB}}$ refers as the black body temperature, of which temperature is $60^{\circ} \mathrm{C}$, and appears in purple (or lighter in a greyish scale) in the luminance color scale.

Table 1: Variation of the reflectance and of the emissivity and values of the emissity in the inserted (-1.9 V) and deinserted $(1.0 \mathrm{~V})$ state for $\mathrm{WO}_{3}$ thin films of various thicknesses on Au or FTO substrates cycled in $\mathrm{Pt} / \mathrm{H}_{3} \mathrm{PO}_{4}(0.1$ $\mathrm{M}) / \mathrm{WO}_{3}$ cell.

\begin{tabular}{|c|c|c|c|}
\hline & $\mathbf{M W}(\mathbf{2 - 5} \boldsymbol{\mu m})$ & $\mathbf{L W}(\mathbf{8 - 1 2} \boldsymbol{\mu m})$ & $\mathbf{M W}$ and $\mathbf{L W}$ \\
\cline { 2 - 4 } & $\mathrm{WO}_{3}(320 \mathrm{~m}) / \mathrm{Au}$ & $\mathrm{WO}_{3}(650 \mathrm{~nm}) / \mathrm{FTO}$ & $\mathrm{WO}_{3}(650 \mathrm{~nm}) / \mathrm{Au}$ \\
\hline$\Delta \mathbf{R}(\boldsymbol{\%})$ & 73 & 50 & $42(\mathrm{MW}) / 33(\mathrm{LW})$ \\
\hline$\Delta \boldsymbol{\varepsilon}$ & 0.78 & 0.49 & $0.51(\mathrm{MW}) / 0.38(\mathrm{LW})$ \\
\hline $\begin{array}{c}\text { Level: } \\
\boldsymbol{\varepsilon}_{\text {inserted }} / \boldsymbol{\varepsilon}_{\text {deinserted }}\end{array}$ & $0.86 / 0.08$ & $0.74 / 0.25$ & $\begin{array}{c}0.76 / 0.25(\mathrm{MW}) \\
0.55 / 0.17(\mathrm{LW})\end{array}$ \\
\hline$\Delta \mathbf{T}\left({ }^{\circ} \mathbf{C}\right)$ & 35 & 21 & $30(\mathrm{MW}) / 15(\mathrm{LW})$ \\
\hline
\end{tabular}




\subsection{2. $\mathrm{ZnO}$}

Transparent Conducting Oxides are key players in the kinetics of ECDs. Among them, indium tin oxide (ITO) remains the state of the art [13]. Besides excellent optoelectronic properties, the as-made ITO transparent electrodes suffer from major limitations like costly fabrication process and brittleness as well as a high environmental impact as reported by Posset et al. from Life Cycle Assessment study [14]. Indeed, the instability of ITO to mechanical constraints prevents its use for fabrication of flexible devices. The use of solution-processable nanomaterials appears as a promising alternative since it affords a low-temperature, large area and low-cost deposition method for transparent flexible electrodes. Recently significant work has been carried out using carbon nanotubes, graphene and metallic nanowires [1516]. In respect of solid state device, Zinc Oxide based thin films appear to be a nice alternative to ITO. High conductivity is usually reported by Gallium or Aluminum doping, whereas aiming at an increase in conductivity by increasing the electron concentration, we investigated tetravalent dopants. Among Sn, Ge and Si dopants, Si doped $\mathrm{ZnO}$ thin films, called SZO, showed the highest performances. A resistivity as low as $3.310^{-4} \Omega \mathrm{cm}$ with a transmittance of about $80 \%$ was reported for SZO thin films doped with $1.5 \%$ of Si deposited by the pulsed laser deposition technique at room temperature [17]. As earlier, pointed out PLD remains an ideal technique for screening composition, the common apparatus are limited to low surface area deposition preventing from further commercialization. Using the sputtering technique, the promising results were extended to SZO thin films deposited on larger area substrate [18]. Indeed, in addition of the common optimized parameters which includes the deposition pressure, the substrate temperature, we demonstrated higher performances for SZO thin films for which a target pre-sputtering step was applied. The presputtered step consist of sputtering the target in the usual deposition conditions during $80 \mathrm{~min}$, with a mask positioned between the target and the substrate avoiding any deposition onto the substrate. The comparison of the evolution of the resistivity, measured by Hall effect measurements, versus the temperature substrate, displayed in Fig. 6, show smaller values when a pre-sputtering step is applied. The decrease in resistivity is associated with an increase in carrier concentration. For instance, for a substrate temperature of $150{ }^{\circ} \mathrm{C}$, the carrier concentration of the SZO thin films deposited with or without pre-sputtering step increases from 2.5 to $3.7510^{20} \mathrm{~cm}^{-3}$ while the mobility is in between 10 to $16 \mathrm{~cm}^{2} / \mathrm{V}$.s. In order to estimate the quantity of active $\mathrm{Si}^{4+}$ in substitution of $\mathrm{Zn}^{2+}$, theoretical carrier concentration was calculated by the (1) equation :

$N_{t h}=\frac{\%_{S i} \cdot n_{\text {extra_electron }} \cdot \rho \cdot N_{A}}{M}$

where: $\%_{\mathrm{Si}}$ is atomic quantity of silicon, $\mathrm{n}_{\text {extra_electron }}=2$ the number of electron added by each substitution of $\mathrm{Zn}^{2+}$ by $\mathrm{Si}^{4+}, \mathrm{N}_{\mathrm{A}}$ Avogadro constant $\left(\mathrm{N}_{\mathrm{A}}=6.022 \times 10^{23} / \mathrm{mol}\right)$, and $\mathrm{M}$ molar mass of $\mathrm{ZnO}(\mathrm{M}=81.408 \mathrm{~g} / \mathrm{mol})$. The comparison of the calculated and measured carrier concentration value shows the presence of only $10 \%$ of active sites in $\mathrm{S}_{3 \%} \mathrm{ZO}$ increasing to $48 \%$ for $\mathrm{S}_{1.5 \%} \mathrm{ZO}$. However, such interpretation assuming the presence of $\mathrm{Si}^{4+}$ cations appears too simple in respect of X-ray photoelectron Spectroscopy results. Indeed, as reported by other authors [19], XPS measurements indicate the existence of $\mathrm{Si}$ cation in a lower oxidation state than 4, namely in between 1 and 3. Interestingly, using similar deposition conditions, XPS measurements performed on $\mathrm{SiO}_{2}$ thin films confirm a 4+ oxidation state for $\mathrm{Si}$ cations. In addition, the modification of the O1s XPS spectrum with Si addition suggests an increase in the proportion of the intermediate contribution attributed to oxygen deficient environment or to $0^{-}$state. As XPS measurements are related to surface measurements, Electron Energy Loss Spectroscopy (EELS) analyses were performed on SZO thin films. The film spectra were compared with the $\mathrm{Si}(\mathrm{L} 2,3)$ peak of silica nanopowder (Sigma Aldrich, $>99.5 \%$ ). Due to the low content of silicon in the film, the $\mathrm{Si}(\mathrm{L} 2,3)$ peak signals of the films were low. Hopefully, the edge of all the peaks appeared clearly. The $\mathrm{Si}(\mathrm{L} 2,3)$ peak of all the films are shifted to lower energy than the powder. This suggests that the oxidation state of $\mathrm{Si}^{\mathrm{n}+}$ is lower than 4+ (Fig. 7). The nature of the defects in $\mathrm{SZO}$ thin films, at the origin of the evolution of the resistivity with $\mathrm{Si}$ addition is still unclear. Indeed, additional parameters than the stoichiometry have to be considered as shown by Treharne et al. [19] reporting that the carrier transport mechanisms within the material are dominated by grain boundary scattering. 


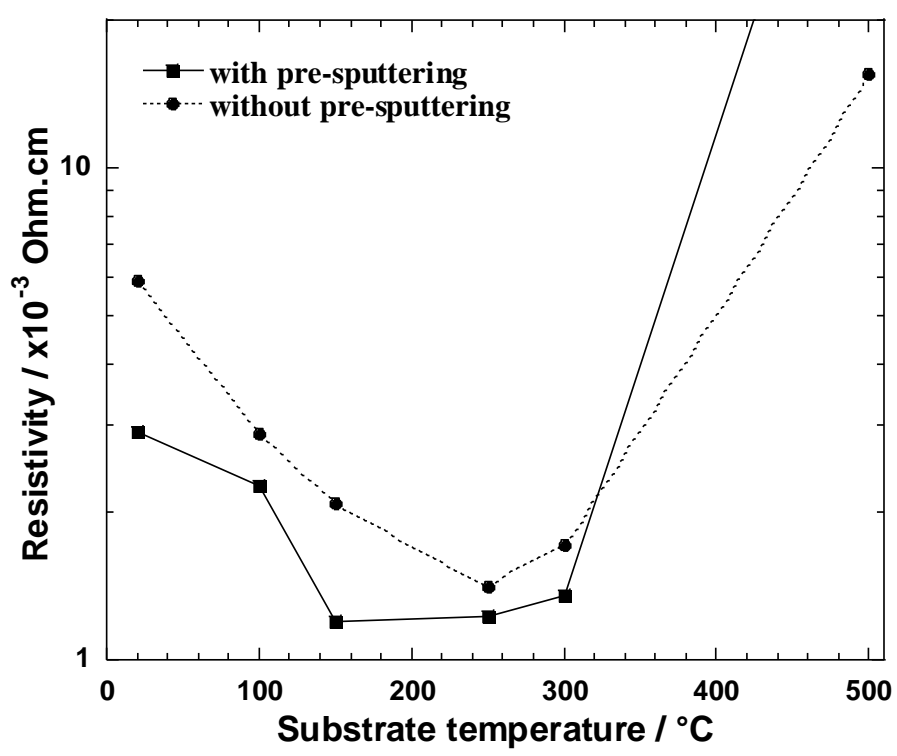

Figure 6: Evolution of the resistivity vs. substrate temperature of SZO thin films deposited by sputtering with and without pre-sputtering.

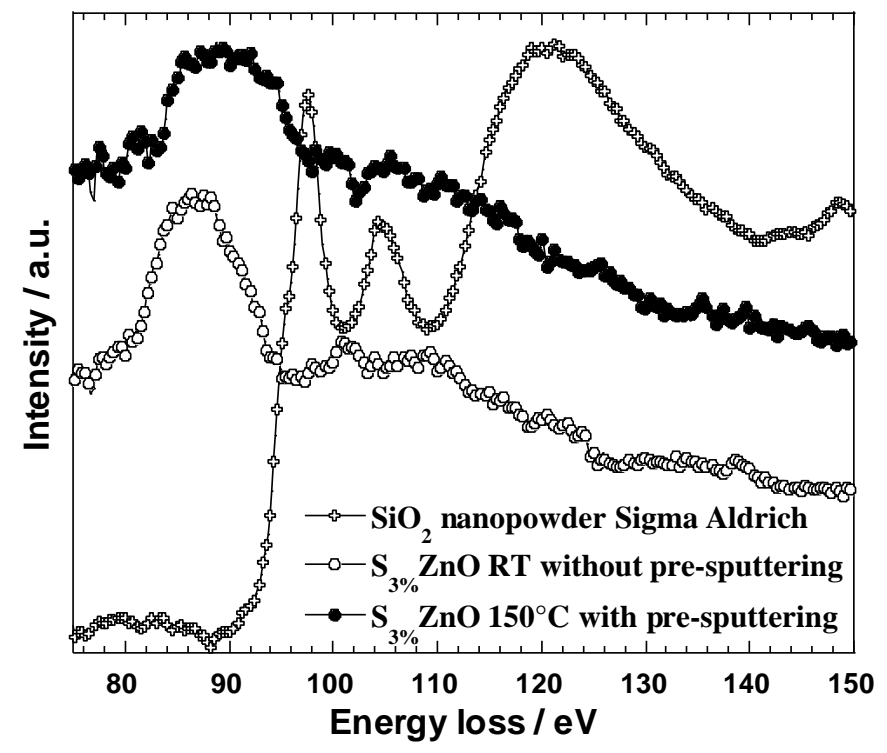

Figure 7: EELS spectra of $\mathrm{SZO}$ thin films, and of $\mathrm{SiO}_{2}$ nanopowder. 


\subsubsection{Devices}

As earlier stated, electrochromic devices are commonly based on a five layers configuration described by the TCO/EC1/Elec./EC2/TCO chain (Figure 1). The deposition of the successive layers, taking into account the control of interfaces, is commonly carried out using physical vapor deposition techniques, and more specifically sputtering. Aiming at facilitating the device manufacture as well as reducing the cost, special attention has been devoted to the reduction of the number of layers, i.e. devices of less than 5 layers. Such goal was achieved by using an electrochromic layer showing in addition of its change in optical properties a good electronic conductivity, playing then the role of both conductive and active layer. This simple statement is already illustrated when using conductive polymers (CEC) such as PSS-doped PEDOT whereas oxide thin films exhibiting both electrochromism as well as high electronic conductivity are quite rare. PSS-doped PEDOT is electrochemically active and exhibits cathodic electrochromic properties (i.e. colored in the reduced state) making it suitable as the active and conducting element in ECDs applications. In addition, herein we introduce an original concept of using a metallic layer behaving as both the conductive layer as well as counter electrode. Figure 8 displays in a schematic way the simplification of the EC device associated with the reduction of the number of layers leading to 4 layer-ECD and 3 layer-ECD. The 4-layer ECD results from the replacement of the conductive layer and the counter electrode by a single layer, which is here a metal. In addition to the previous configuration, the replacement of conductive layer and the active electrode by a single layer leads to the 3-layer devices. Figure 9a reports the chronoamperogramms of a 4-layer ECD, consisting of PET/ITO/PEDOT/(0.3 M) LiTFSI/BMITFSI. $40 \%$ PMMA/Ag/paper, cycled in between $0 \mathrm{~V}$ to $-0.7 \mathrm{~V}$ for periods of $120 \mathrm{~s}$. while the in-situ reflectance recorded at open circuit voltage, $0 \mathrm{~V},-0.7 \mathrm{~V}$ and $-1 \mathrm{~V}$ is shown in Figure 9b. 4-layer ECD switches from a light blue to deep blue upon reduction from $0 \mathrm{~V}$ to $-0.7 \mathrm{~V}$. Interestingly, the reflectance spectrum recorded at $-0.7 \mathrm{~V}$ is very close to the one measured at $-1 \mathrm{~V}$, suggesting that an electrochemical window of $0.7 \mathrm{~V}$ is sufficient for reaching nice performances with a modulation of the contrast in reflectance in between 350 and $700 \mathrm{~nm}$ (Fig. 9b) at $550 \mathrm{~nm}$ of about $4.4 \%$ i. e. from 25.34 $\%$ to $29.74 \%$. The limitation of the voltage window is in good agreement with our final goal of low power device as demonstrated by the possible activation of the device using a smartphone.

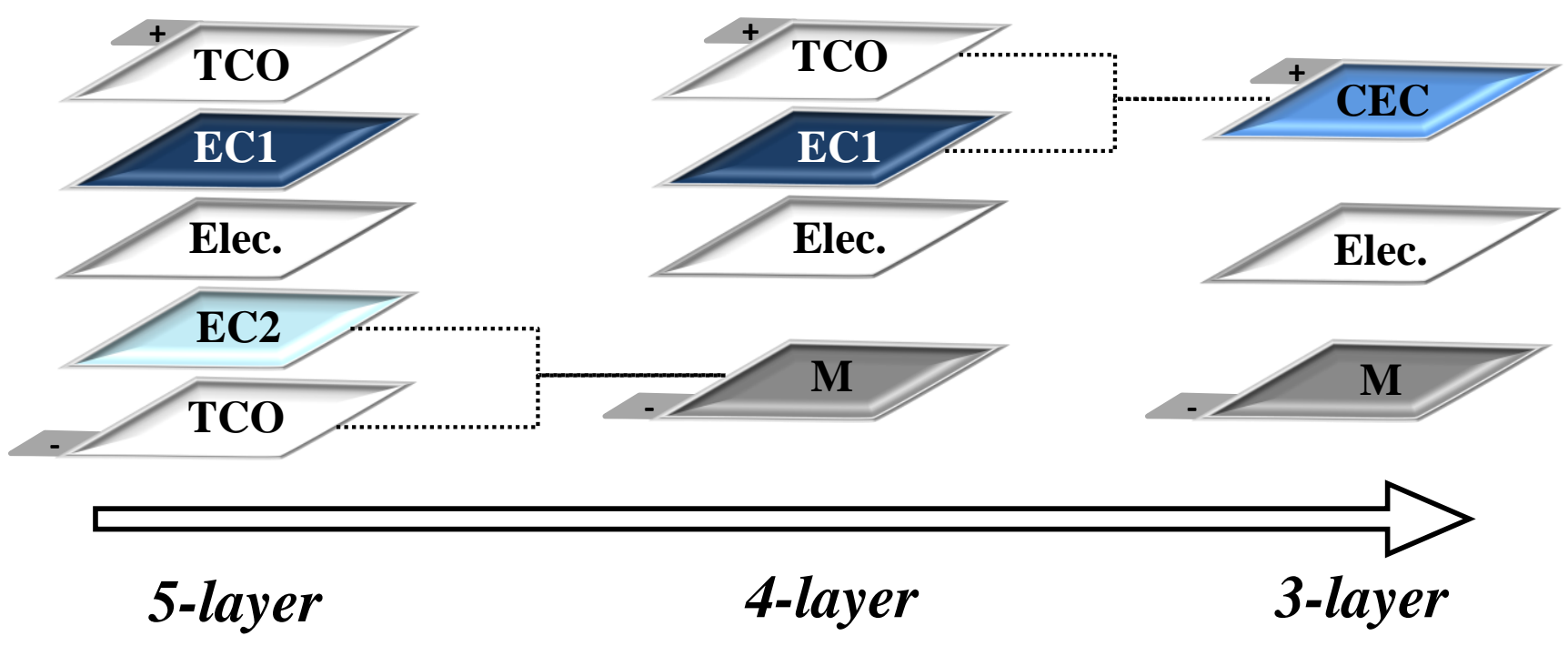

Figure 8: Simplification of the electrochromic device architecture from five layers to four and three layers. TCO stands for transparent conducting oxides, EC1 and EC2 for electrochromic layers, Elec. for electrolyte, M for metal counterelectrode and CEC for conductive electrochromic layer. 

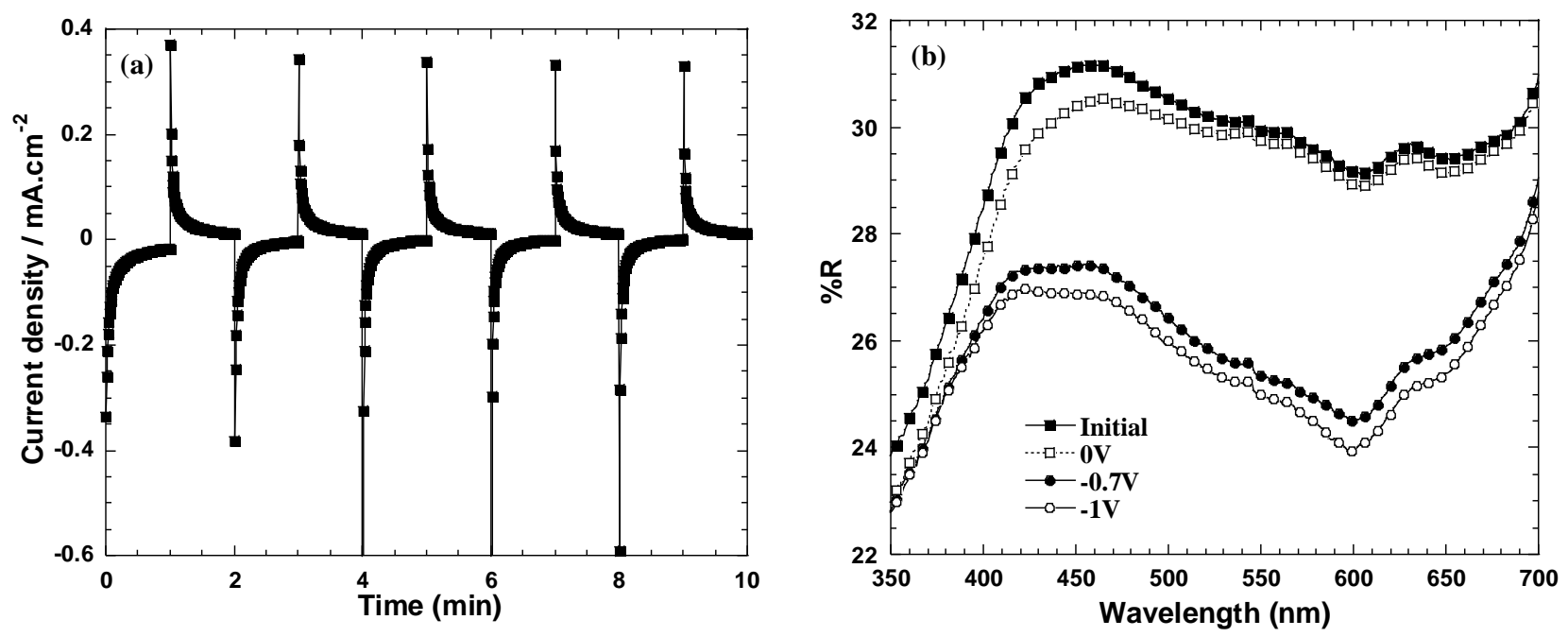

Figure 9: (a) Chronoamperogramms at $-0.7 \mathrm{~V}$ and $0 \mathrm{~V}$ for periods of $120 \mathrm{~s}$ of 4-layer ECD: PET/ITO/PEDOT/(0.3 M) LiTFSI/BMITFSI. $40 \%$ PMMA/Ag/paper, (b) reflectance curves of initial, bleached at $0 \mathrm{~V}$, and colored respectively at $0.7 \mathrm{~V}$ and at $-1 \mathrm{~V}$.

\section{CONCLUSIONS}

The design and optimization of electrochromic devices, which optical properties are modified under an applied voltage are strongly related to the targeted applications. In transmission or in reflection, in the visible or in the infrared region, an improvement of the ECDs performances will result from both an optimization of each single layer as well as of the full device. Herein, by adjusting the synthesis parameter leading to better film homogeneity, electrochromic properties in the visible are reported for $\mathrm{WO}_{3}$ thin films deposited on paper using a novel method. Using physical deposition methods, the morphology and the thickness of $\mathrm{WO}_{3}$ thin films appear as key parameters in respect of their properties in the IR region. Si doped $\mathrm{ZnO}$ thin films are shown to be good candidate as TCO layer but the mechanism of improved electronic conductivity is still to be determined. Finally, in an original approach, simplified architecture of 5layer battery type ECD is illustrated for low power device.

\section{ACKNOWLEDGEMENTS}

The authors wish to thank the ANR PEPS for financial support. In addition, the research leading to some of the results has received funding from the European Community's Seventh Framework Programme (FP7) undergrant agreement no. 200431 (INNOSHADE).

\section{REFERENCES}

[1] S.K. Deb, “A Novel Electrophotographic System”, Applied Optics 8, 192-195 (1969).

[2] http://www.gentex.com/automotive/mirror-module/

[3] C. Ma, C. Xu, "Smart goggles based on all-plastic electrochromic devices", Proc. SPIE 7493 (2009).

[4] A. Azens, G. Gustavsson, R. Karmhag, C.G. Granqvist, "Electrochromic devices on polyester foil", Solid State Ionics 165(1-4), 1-5 (2003).

[5] C. Lampert, "Chromogenic smart materials", Materials Today, 7(3), 28-35 (2004).

[6] http://sageglass.com/technology/how-it-works/ 
[7] K. Sauvet, L. Sauques, A. Rougier, "IR electrochromic $\mathrm{WO}_{3}$ thin films : from optimization to devices", Solar Energy Materials and Solar Cells, 93(12), 2045-2049 (2009).

[8] A. Teissier, J. P. Dubon, P. H. Aubert, F. Vidal, S. Remaury, J. Crouzet, C. Chevrot, "Feasibility of conducting semiIPN with variable electro-emissivity: A promising way for spacecraft thermal control", Solar Energy Materials and Solar Cells, 99, 116-122 (2012).

[9] C. G. Granqvist, Handbook of Inorganic Electrochemical Materials, Elsevier, Amsterdam, (1995).

[10] P. M. S. Monk, R. J. Mortimer, D. R. Rosseinsky, Electrochromism and Electrochromic Devices, Cambridge University Press, Cambridge, UK (2007).

[11] A. Danine, L. Cojocaru, C. Faure, C. Olivier, T. Toupance, G. Campet and A. Rougier, "Room Temperature UV treated $\mathrm{WO}_{3}$ thin films for electrochromic devices on paper substrate", Electrochimica Acta, 129, 113-119 (2014).

[12] K. Sauvet, A. Rougier, L. Sauques, "Electrochromic $\mathrm{WO}_{3}$ thin films active in the IR region", Solar Energy Materials and Solar Cells, 92(2), 209-215 (2008).

[13] C.G. Granqvist, "Electrochromics for smart windows: Oxide-based thin films and devices", Thin Solid Films, 564, $1-38$ (2014).

[14] U. Posset, M. Harsch, A. Rougier, B. Herbig, G. Schottner, G. Sextl, "Environmental assessment of electrically controlled variable light transmittance devices", RSC Advances, 2(14), 5990-5996 (2012).

[15] A.K. Geim, "Graphene: Status and prospects", Science, 324(5934), 1530-1534 (2009).

[16] D. Langley, G. Giusti, C. Mayousse, C. Celle, D. Bellet, J.-P. Simonato, "Flexible transparent conductive materials based on silver nanowire networks: A review", Nanotechnology, 24(45), 452001 (2013).

[17] J. Clatot, G. Campet, A. Zeinert, C. Labrugère, M. Nistor, A. Rougier, "Low temperature Si doped ZnO thin films for transparent conducting oxides", Solar Energy Materials and Solar Cells, 95, 2357-2362 (2011).

[18] C. Faure, J. Clatot, L. Teule-Gay, G. Campet, C. Labrugère, M. Nistor, A. Rougier, "Co-sputtered ZnO:Si thin films as transparent conductive oxides", Thin Solid Films, 524, 151 -156 (2012).

[19] A.K. Das, P. Misra, L.M. Kukreja, "Effect of Si doping on electrical and optical properties of ZnO thin films grown by sequential pulsed laser deposition", Journal of Physics D: Applied Physics, 42, 165405-165412 (2009).

[20] R.E. Treharne, L.J. Philipps, K. Durose, A. Weerakkody, I.Z. Mitrovic, S. Hall, "Non-parabolicity and band gap renormalisation in Si doped ZnO”, Journal of Applied Physics, 115, 063505 (2014). 